In these turbulent times the Triumvirate bring you the October Airwaves with a little help from a selection of super heroes.

\section{A STOUT AVENGER...}

Thor is a super hero in the form of a Scandinavian god who features in the recent film 'Avengers: Endgame'. The movie sees Thor fight a battle with obesity as the drunken ruler of a group of refugees in Norway. The global problem of obesity is highlighted by another group of Scandinavians in this month's Thorax (see page 958). Ekström and colleagues studied the relationship between obesity and breathlessness in over 13000 individuals in their late fifties - around 10\% of whom reported breathlessness. They found that obesity increased the risk of breathlessness more than threefold and that the relationship was independent of age, sex, smoking, airflow obstruction, exercise level and comorbidities. At the end of "Endgame" Thor appoints Valkyrie as the new ruler of his people and goes off to join the Guardians of the Galaxy. We are not told whether he manages to lose all the extra pounds and overcome the associated shortness of breath.

\section{ANTMAN}

The film Antman (and its sequel) focuses on one of the Avenger super heroes who can shrink himself to the size of an ant, using a special suit. The story is exceptionally convoluted with numerous digressions into the 'Quantum Realm'. A state of the art review in this month's journal (see page 965) also focuses on the technology of small things - 'nanotechnology' - but is a great deal less convoluted and does not invoke the 'Quantum Realm'. Potential applications of nanotechnology include: a gene therapy vector for cystic fibrosis; a diagnostic system to detect the biomarkers ESAT-6 and CFP-10 in tuberculosis; and the use of an 'eNose' device to differentiate inflammatory phenotypes of asthma, using 'breath-print'. We can expect another instalment in the profitable
Antman franchise. If nanotechnology lives up to the hype it may also be extremely profitable and a 'game- changer' for medical practice.

\section{HUNTRESS}

DC comic's superheroes are among the most recognisable of all time and include Superman, Batman, Wonderwoman and this editor's particular favourite, Flash. But the real DC superhero may well be Flt3L. Dendritic Cells (DCs) have emerged as an important cell in the development of pulmonary fibrosis although their role is uncertain. In this issue of Thorax (see page 947) Tarrés et al describe how elevated Flt $3 \mathrm{~L}$ is found in the lung and serum of patients with IPF. Studies in experimental models demonstrated that the Flt3L was required to limit fibrosis suggesting that this response needs to be augmented rather than inhibited if fibrosis is to be ameliorated. Much like DC comics Huntress, prone to outbreaks of extreme violence and originally the villain of Golden Age, she later turned out to be a superhero!

\section{CAPTAIN AMERICA}

In attack of the Asthma Monster, Captain America takes on obstructive airways disease and beats the monster, through his own experience of beating asthma as a child by remaining calm in times of stress and avoiding inhaled medication?! Maybe he realised that not all obstructive airways disease is asthma and was even smarter than his creators imagined! In this edition of Thorax (see page 999) Johnson and Johnson show that although obstructive airways disease is common the use of inhaled medication does not improve lung function and is in fact increased medication use is associated with a greater reduction in FEV1. It is highly unlikely that Captain America had LAM and despite his superhero status he clearly doesn't understand the benefits of controlled trials, but there is certainly the need for the role of inhaled medication to be further evaluated in patients with LAM.

\section{DIFFERENCE BETWEEN HEROES AND SUPER HEROES}

A superhero is a fantasy fiction crimefighting character, often with supernatural powers or equipment, whereas a hero is a real person who has carried out an extraordinary deed. This difference may have been the driver for Rachael Evans and Sally Singh (see page 994) investigating the minimum important difference (MID) of the incremental shuttle walk test (ISWT) in patients with COPD before and after pulmonary rehabilitation (PR) and for Claire Nolan and colleagues (see page 996) investigating the difference between home-based exercise and outpatient PR. Unlike the obvious differences between our clinical heroes, such as Florence Nightingale and Alexander Fleming, and the less impressive super heroes, the MID for ISWT in COPD was shown to be between $35 \mathrm{~m}$ to $36 \mathrm{~m}$ with less improvement in exercise capacity shown from home based treatment. All these investigators should assemble to become the COPD Avengers.

\section{ANOTHER JOB FOR ANTMAN?}

Our teaser image relates to a case of post-prandial abdominal pain. Antman could be deployed but Embosphere microspheres did the job.

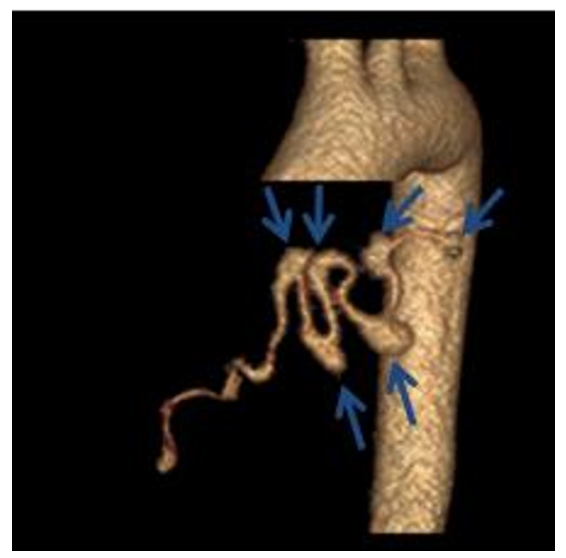

(C) Author(s) (or their employer(s)) 2019. No commercial re-use. See rights and permissions. Published by BMJ. 